\title{
Development of 1200A AC/DC Linear Standard Power Supply Feipeng Lin ${ }^{1, a}$, Hong Zhang ${ }^{2, b}$, Huanghui Zhang ${ }^{3,4, c^{*}}$, Wei Zhao ${ }^{1, d}$, Haiming Shao ${ }^{1, e}$
}

1. Division of Electromagnetic Metrology, National Institute of Metrology, Beijing 100013, China

2. Shanghai Institute of Measurement and Testing Technology, Shanghai 201203, China

3. School of instrumentation science and opto-electronics engineering, BeiHang University, Beijing 100191

\author{
4. Fujian Metrology Institute, Fuzhou 350001 \\ alinfp@nim.ac.cn, bzhangh@simt.com.cn, ‘fjzhh52@163.com
}

\begin{abstract}
Keywords: Linear Power, AC, High Current, Ripple Wave
Abstract. With the development of science, technology and production, there is an increasing demand for high-current power supply, which is widely applied in research of high-speed railways, subways, electric cars, DC transmission and electromagnetic measurement science. The commercial high-current power supply basically uses the form of switching power supply and its ripple wave is generally greater than $1 \%$, with the peak-peak value up to the pulse ripple shortcomings of a few volts (with a constant amplitude), and the ripple wave basically has nothing to do with the amplitude of the output current. Therefore, it is very difficult for switching power to be applied in high-current AC power supply. In this paper, we have researched and designed a kind of AC/DC linear high-current power supply based on the linear theory. In this paper, we have researched and designed a kind of AC/DC high-current power supply based on the linear theory, with the AC current frequency kept from $50 \mathrm{~Hz}$ to $1 \mathrm{kHz}$. Moreover, a plan has been designed to test the $\mathrm{AC} / \mathrm{DC}$ high-current performance and assess the accuracy, ripple wave (harmonic wave) and short-term drift performance of the power supply.
\end{abstract}

\section{System Principle and design}

The linear current supply means that the power supply has no break variable or pulse superposition in the process of current output. DC current supply has better stability and a small ripple coefficient, while AC current supply has smaller distortion and better stability.

Commonly, a high-current DC power supply above $1 \mathrm{kA}$ usually adopts direct mains supply rectification and the low output voltage will result in a larger ripple wave (above $2 \%$ ) and poor stability (about $0.2 \% / 3$ minutes), because the output current will change with the circuit resistance of the power grid and power supply. Therefore, the solution of the above-mentioned problems requires an adjustable and stable AC supply featuring a higher frequency (above $1 \mathrm{kHz}$ ) and free of power frequency modulation by means of rectification and filtration. AC current supply is even more demanding.

To sum up, the high power amplifier (HPA) should be the core component for research and design of AC/DC linear high-current supply, requiring that the power amplifier amplitude can be adjusted (in an intelligent manner) and have a higher common mode rejection ratio. Moreover, DC current supply is provided with an efficient rectification and filtration assembly. The short-term stability of AC/DC current supply depends on the simulative closed-loop system while the long-term stability depends on the SCM (single chip microcomputer) digital closed-loop system subject to automatic tracking.

See Fig. 1 for the schematic block diagram of the power supply for research and design: After filtration, the grid $220 \mathrm{~V}(50 \mathrm{~Hz})$ current goes through the isolation transformer, the rectification and filtration circuits as well as a power amplification circuit. Then, an AC or DC high-power current will be output through current boosting, filtration and current sampling feedback control. 


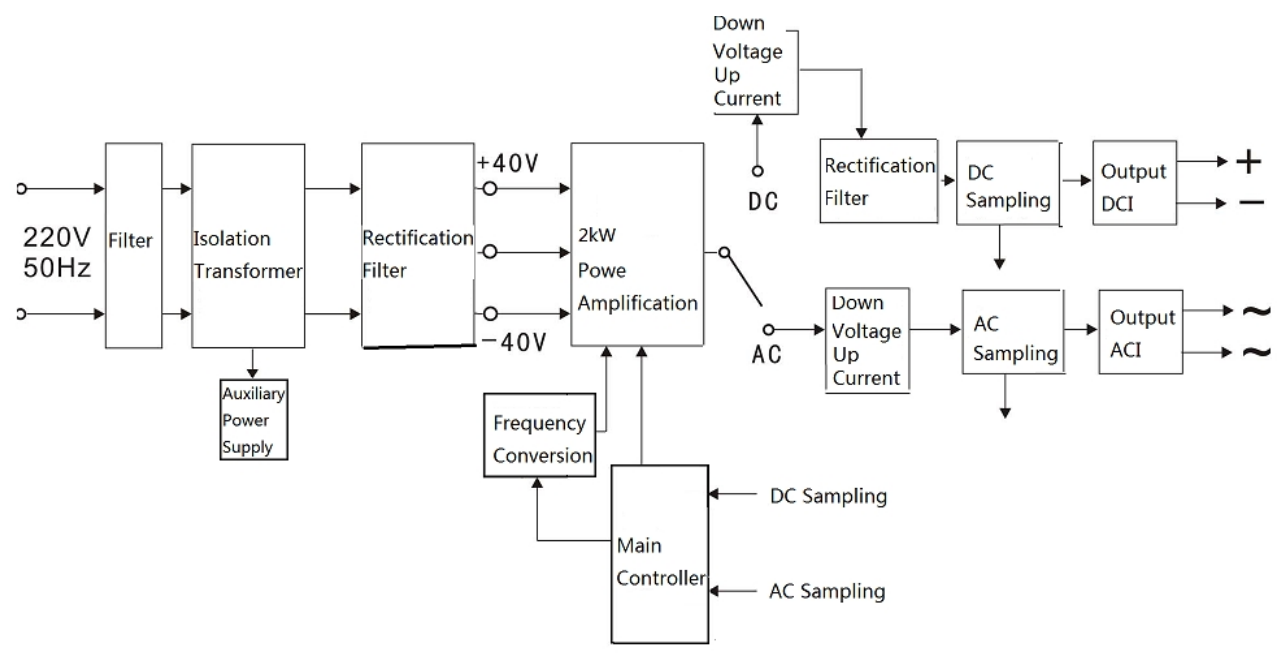

Fig. 1 Schematic block diagram

From the design principle, it can be seen that the development of AC/DC high-current supply includes such key and difficult points as follows: isolation transformer matching, power frequency rectification and filtration, power amplifier, DC step-down current-boosting devices, DC rectification assembly, DC filtration assembly, AC/DC sampling and AC step-down and current-boosting, etc.

\section{Design essentials for key components}

\section{Development of $2 \mathrm{~kW}$ power amplifiers}

Fig.2 and Fig.3 show the matching isolation transformer and the rectifier bridge respectively. According to the theoretical calculation, the power amplifier for a $1 \mathrm{kA} \mathrm{AC/DC} \mathrm{power} \mathrm{supply} \mathrm{should} \mathrm{have}$ its maximum working current about $80 \mathrm{~A}$; in order to improve the reliability, 8 power modules (The maximum current and withstand voltage should be above $200 \mathrm{~A}$ and $500 \mathrm{~V}$ respectively for each power module) are adopted.

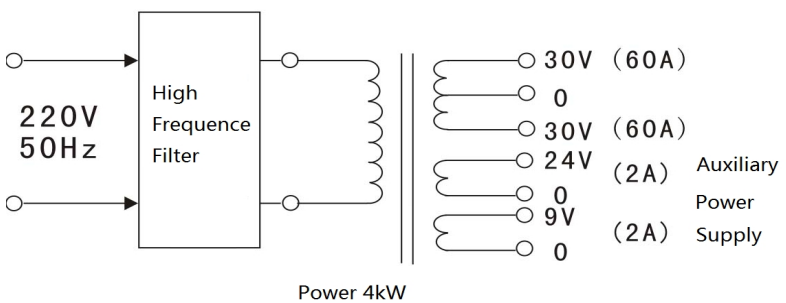

Fig.2 Principle of isolation transformer

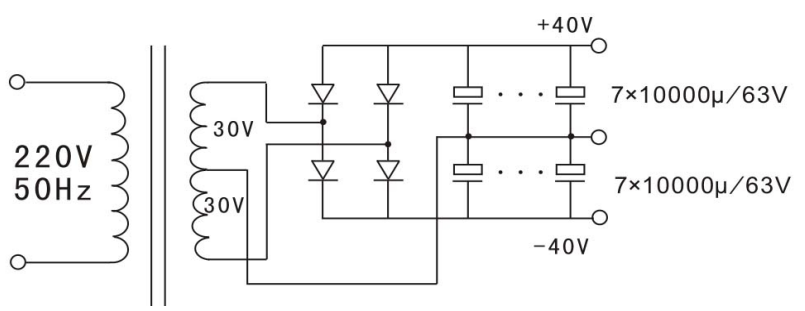

Fig.3 Rectifier Bridge 
The whole power amplifier has a fairly excellent common mode rejection ratio (CMRR) to ensure that $50 \mathrm{~Hz}(100 \mathrm{~Hz})$ will not activate modulation of the current output.

Hint: The power frequency (and its frequency doubling) modulation signal will produce beat frequency interference in the AC current supply. For a DC current supply, its ripple coefficient will be increased and the ripple wave is difficult to remove in a conventional manner.

\section{DC step-down current boosting}

Each transformer coil has inherent inductance, so a higher frequency is no doubt good for filtering, but the output efficiency of the power amplifier will consequently be lower, which is a disadvantage in the linear power supply, as shown in Fig.4. We choose the frequency of $1 \mathrm{kHz}$ as a compromise.

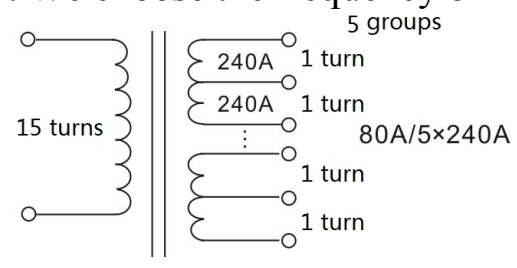

Fig.4 Principle of current boosters

\section{DC rectifier}

The output voltage of the AC current supply is only $1.5 \mathrm{~V}$, so it requires that finally there should be a $0.5 \mathrm{~V} / 1200 \mathrm{~A}$ output after rectification and filtration. This is indeed a very difficult task, the tube voltage drop of a Schottky rectifier tube (if used in design) is $0.4 \mathrm{~V} \sim 0.7 \mathrm{~V}$; if a full-wave rectifier (not a bridge rectifier) is used and we use a Schottky module $(300 \mathrm{~A} / 30 \mathrm{~V})$ characterized by a high current and a low voltage drop, the rectifier tube loss will be below $0.5 \mathrm{~V}$ and two filter inductance coils will suffer from the loss of $0.15 \mathrm{~V}$. The sampling DC resistance diverter will suffer from the loss of $0.1 \mathrm{~V}$ and the step-down on the whole lead will be about $0.2 \mathrm{~V}$. A $1.5 \mathrm{~V}$ AC voltage will provide a $1.3 \mathrm{~V}$ DC voltage theoretically after rectification. Therefore, connect the lead and adopt $2.5 \mathrm{~A} / \mathrm{mm} 2$ as the current density of the transformer coil lead. Reduce the resistance value of the sampling resistor and the loss will be reduced, but, at the same time, the noise will increase while the accuracy will drop. Select a 300A/30V rectifier tube and let it working only at around 50A; a Schottky module uses a total of twenty $300 \mathrm{~A} / 30 \mathrm{~V}$ rectifier tubes and then the voltage drop at its both ends will drop to $0.4 \mathrm{~V}$.

\section{DC filter}

It adopts a 5-way double filtering network as shown in Fig.5:

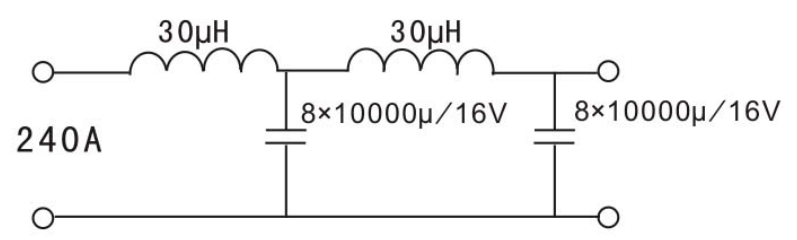

Fig. 5 type filtering network

The single-stage AC attenuation ratio is 1:40 while the two-stage 1:1600, which can ensure that the ultimate current ripple coefficient is less than $0.1 \%$ (about $0.05 \%$ ). For such a filter circuit, if the frequency is reduced by 20 times (namely, power frequency), the $\mathrm{AC}$ attenuation ratio is 1:1.25 and then 
the power frequency ripple wave almost cannot be filtered, so that it is extremely difficult to filter the high-current power frequency ripple wave.

\section{DC current sampling}

The most classic and reliable way is to use sampling resistors (diverters) for DC current sampling, as long as the thermal stability of resistors can be ensured, then the resistor accuracy can be enhanced (The temperature control standard resistors have their resistance values of $80 \mu \Omega$ and $800 \mu \Omega$ respectively). In case of a $1200 \mathrm{~A}$ current, the voltage drop is $96 \mathrm{mV}$, the current below $100 \mathrm{~A}$ is set as $800 \mu$ 的 this resistor still can guarantee the accuracy of $0.01 \%$ if the ambient temperature is kept at $10^{\circ} \mathrm{C} \sim 35^{\circ} \mathrm{C}$. The working principle of this resistor is as follows: The internal preheating device first heats the resistor to the temperature of $32^{\circ} \mathrm{C}$. When the internal sensor detects the temperature beyond $32^{\circ} \mathrm{C}$, the fan will start to cool the resistor radiator, so that the resistor could always be controlled at the temperature of $32^{\circ} \mathrm{C} \sim 38^{\circ} \mathrm{C}$ , within which the resistor can have its resistance change less than $0.005 \%$.

\section{AC step-down current boosting}

The power amplifier is working at the state of $\mathrm{AC}$ output, and when the external load is approximately short-circuited, the power amplifier tube will bear great power consumption, so that the heat dissipation could be ensured by joint function of the fan rotational speed and temperature, as shown in Fig.6.

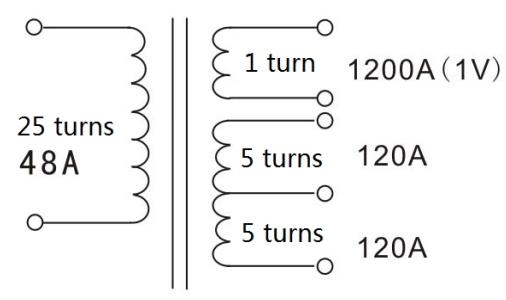

Fig. 6 AC step-down current boosting

7. AC sampling

The AC sampling adopts heart-through combined instrument transformers, as shown in Fig.7.

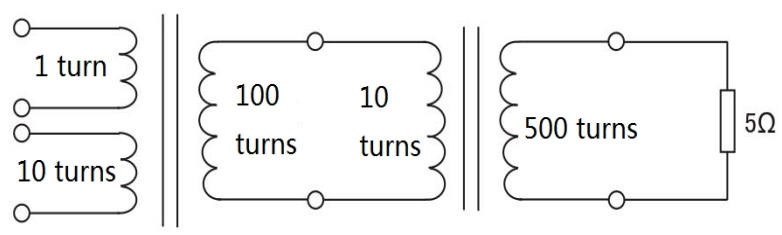

Fig. 7 AC sampling

The above instrument transformer combination structure can not only greatly reduce the power consumption of the sampling resistor, but also significantly reduce the $1 \mathrm{kHz}$ errors. 


\section{Main controller}

The main controller is the brain of the power supply, mainly undertaking to:

(1) Change the output frequency, $50 \mathrm{~Hz}, 60 \mathrm{~Hz}, 400 \mathrm{~Hz}$ and $1 \mathrm{kHz}$.

(2) Complete closed-loop control and tracking the scale of the output current and ensure the stability and accuracy of the current output.

(3) Display: Display the real-time scale of the output current.

(4) Safety protection: Automatically disconnect the signal source in time of no load, overload and overheat, so that the power amplifier could have no output.

In the main controller, the advanced digital and analog closed-loop technology is simultaneously used to ensure a stable, reliable and accurate output.

\section{Heat dissipation}

This power supply has two large heat generators. The Schottky rectifier will dissipate the power greater than $500 \mathrm{~W}$. The power amplifier tube has its maximum calorific value higher than $1400 \mathrm{~W}$. The air cooling method is adopted and we can control the highest temperature of the radiator under $75^{\circ} \mathrm{C}$ according to the experience and theoretical calculation, but the loud noise is disturbing. Except that a powerful and quiet high-quality fan is used, we also add a control circuit to the fan, so that the fan speed could increase while the radiator temperature is rising. In case of a medium and small current output or a short-time high-current output, the fan noise can be ignored.

\section{Performance test}

There are two difficulties in the performance test, namely, measurement of the DC high-current ripple coefficient and short-term drift and measurement of the AC high-current distortion and short-term drift.

\section{DC ripple test}

For small current ripple test, we often uses a non-inductive resistor and measure the ratio of the AC and DC voltage at both ends, but for an extremely high current, we cannot use an ordinary diverter for sampling as shown in Fig.8. At this moment, the sampling DC voltage is relatively small and the AC and noise voltage could not be identified, so there is no any practical value. For DC switching power supply, this method doesn't work anymore, because the AC frequency of the switching power supply is more than $20 \mathrm{kHz}$ (there is no such high-current non-inductive resistor at all).

(AC voltage millivolts/100) / (DC amperes) is known as the ripple coefficient. Two methods can be used to measure the large current ripple. Firstly, use a Roche coil to directly measure the AC current component. Secondly, use a cored transformer not apt to saturate and an appropriate sampling resistor at the secondary side to measure the AC voltage at both ends of the resistor. Alternatively, an oscilloscope can be used to directly analyze and measure the waveform at both ends.

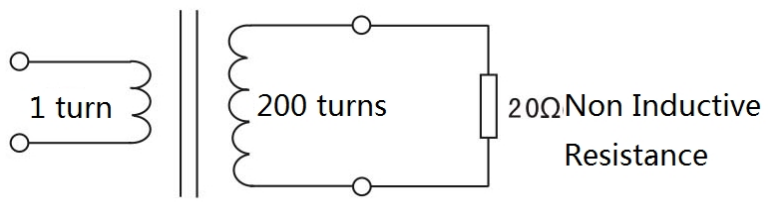

Fig. 8 DC ripple test 
2. Measurement of AC distortion

Sample the voltage on the resistor to measure the distortion as shown in Fig.9 and Fig.10.

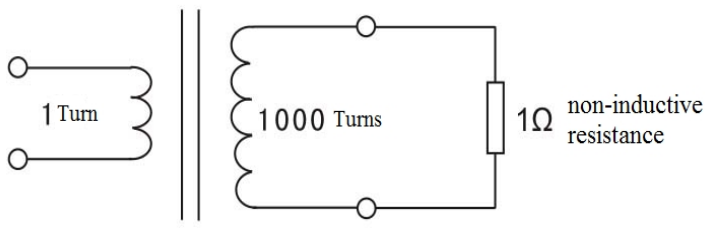

Fig. 9 cored transformer

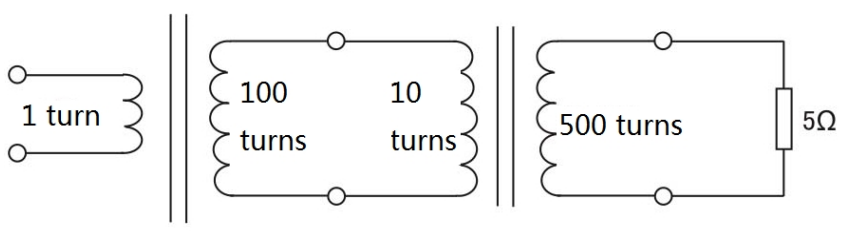

Fig.10 combined instrument transformers

3. Verification of the DC current accuracy

Use a comparison current meter to measure the ground output accuracy of the DC high current supply, as shown in Fig.11. The measurement results are as shown Table 1:

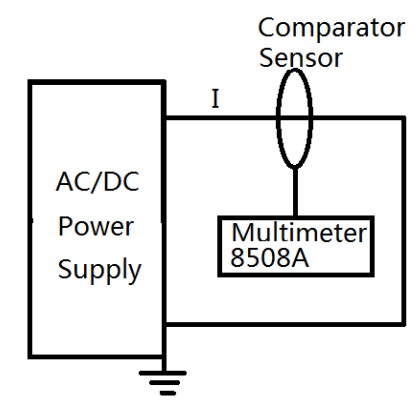

Fig. 11 Principle of the current test

Table 1 Result of the DC accuracy test

\begin{tabular}{|c|c|c|}
\hline Output (A) & Actual (A) & Related Error (\%) \\
\hline 100.00 & 100.00 & 0.00 \\
\hline 500.00 & 500.01 & 0.002 \\
\hline 1000.0 & 1000.1 & 0.01 \\
\hline 1200.0 & 1200.2 & 0.02 \\
\hline
\end{tabular}

4. Verification of the AC current accuracy

Use comparison current sensor, non-inductive resistor and digital multi-meter together to measure the current.

For $400 \mathrm{~Hz}$ and $1 \mathrm{kHz}$, the existing power frequency transformer could not be used any more, and the high-precision power frequency transformer features smaller no-load voltage ratio errors and smaller 
angle differences, but they are all limited within the range of the power frequency. While the frequency is increasing, the core nature and coil distribution parameters will directly affect the final errors as shown in Table 2.

Table 2. Floating-point operations necessary to classify a sample.

\begin{tabular}{|c|c|c|c|}
\hline Output (A) & $50 \mathrm{~Hz}$ Actual Value(A) & $400 \mathrm{~Hz}$ Actual Value(A) & $1000 \mathrm{~Hz}$ Actual Value(A) \\
\hline 100.00 & 100.01 & 100.02 & 100.03 \\
\hline 500.00 & 500.02 & 500.03 & 500.04 \\
\hline 1000.0 & 1000.2 & 1000.3 & 1000.5 \\
\hline 1200.0 & 1200.3 & 1200.4 & 1200.5 \\
\hline
\end{tabular}

\section{Stability test}

As the short-term stability of the reference standard device is superior to $0.001 \%$, the comparison of current sensors, standard resistance and DMMS measuring are used to assess the power short-term stability is a very convenient way. The testing result is illustrated in Table 3.

Table 3. Stability test result

\begin{tabular}{|c|c|c|c|c|}
\hline Status & Actual Value(A) & $50 \mathrm{~Hz}$ Actual(A) & $400 \mathrm{~Hz}$ Actual Value (A) & $1000 \mathrm{~Hz}$ Actual Value (A) \\
\hline Initiation & 100.003 & 100.005 & 100.016 & 100.026 \\
\hline 10 minutes later & 100.003 & 100.003 & 100.014 & 100.024 \\
\hline Initiation & 1200.08 & 1200.28 & 1200.36 & 1200.46 \\
\hline 10 minutes later & 1200.03 & 1200.24 & 1200.30 & 1200.36 \\
\hline
\end{tabular}

\section{Conclusion}

The commercial high-current power supply basically uses the form of switching power supply and its ripple wave is generally greater than $1 \%$, with the peak-peak value up to the pulse ripple shortcomings of a few volts (with a constant amplitude), and the ripple wave basically has nothing to do with the amplitude of the output current. Therefore, it is very difficult for switching power to be applied in high-current AC power supply. In this paper, we have researched and designed a kind of AC/DC high-current power supply based on the linear theory, with the AC current frequency kept from $50 \mathrm{~Hz}$ to 1 $\mathrm{kHz}$. Moreover, a plan has been designed to test the AC/DC high-current performance and assess the accuracy, ripple wave (harmonic wave) and short-term drift performance of the power supply.

\section{Reference}

[1] Chen, Zongmei, "Design of high-accuracy digital controlled direct current power supply". Mechanical Engineering and Green Manufacturing II, MEGM 2012. Vol.155-156, pp.298-302, 2012

[2] Luo, An, Ma, Fujun; Xiong, Qiaopo; He, Zhixing, "The development of high-current power supply system for electrolytic copper foil". Journal of Power Electronics, Vol.15, No.2, pp. 399-410, March, 2015

[3] Xiong, Jun-Hua, Wang, Ting-Ling; Xu, Xing, "Design and development of direct current power supply systems based on TMS320F2812". Power System Protection and Control, Vol. 37, No. 20, pp. 113-116+122, October, 2009

[4] Mkrtchian, J.A., Reznikov, L.N.; Mkrtchian, A.J.,"Water-cooled heavy-current power supply units". INTELEC, International Telecommunications Energy Conference (Proceedings), pp. 397-400, 1995 
[5] Hashimoto, T., Ninomiya, T.; Tanaka, H.; Tymerski, R.P., “ ZVS-PWM-controlled parallel-resonant converter applied to a constant-current power supply". PESC Record - IEEE Annual Power Electronics Specialists Conference, Vol.1, pp. 275-280, 1999.

[6] Hashimoto, T., Ninomiya, T., Tanaka, H., Tymerski, R.P., ZVS-PWM-controlled parallel-resonant converter applied to a constant-current power supply, Source: PESC Record - IEEE Annual Power Electronics Specialists Conference, v 1, p 275-280, 1999

[7] Pei Yunqing, Jiang Guibin, Liu, Haitao, Development of high current power supply for electroplating, IEEE Annual Power Electronics Specialists Conference, v 1, p 21-23, 2002

[8] Mkrtchian, J.A., Reznikov, L.N., etc. Water-cooled heavy-current power supply units, INTELEC, International Telecommunications Energy Conference (Proceedings), p 397-400, 1995

[9] Janoušek, Josef, Tušla, Petr, Direct current power supply for deep-sea mining machine, Proceedings of the ISOPE Ocean Mining Symposium, p 99-103, 2003.

[10]Irie Hisaichi, Yabuuchi, Tomohiro, High-frequency constant-current power supply in noncontact energy transfer system using immittance converter, Electrical Engineering in Japan (English translation of Denki Gakkai Ronbunshi), v 158, n 3, p 81-89, February 2007

[11]Xiong Jun-Hua, Wang Ting-Ling; Xu Xing, Design and development of direct current power supply systems based on TMS320F2812, Dianli Xitong Baohu yu Kongzhi/Power System Protection and Control, v 37, n 20, p 113-116+122, October 16, 2009 Language: Chinese

[12]Wang, Xingnan, Hua, Gongxue, Stable current power supply for the flute type He-Cd+ hollow-cathode laser, Yingyong Jiguang/Applied Laser Technology, v 14, n 2, p 80-81, 58, Apr 1994

\section{AUTHOR BIOGRAPHY}

Feipeng Lin was born in Fujian, China, in 1978.He received BS from Beijing Jiaotong University, China , in 2001. Now he is an Associate Researcher in NIM (National institute of Metrology, China). His research interests include the development of high-voltage and heavy current.

Huanghui Zhang received B.Sc. degree in 2003 from ShanDong University, Weihai, received M.Sc. degree in 2007 from Changsha University of Science \& Technology. Now he is a Ph.D. candidate BeiHang University. His research interest is electromagnetic measurement. 